\title{
Damage development in a sidegrooved CT specimen based on a 3-D endochronic damage model
}

\author{
C.L. CHOW and X.F. CHEN \\ Department of Mechanical Engineering, University of Michigan-Dearborn, Dearborn, MI 48128-1491, USA
}

Received 30 June 1995; accepted in revised form 8 March 1996

\begin{abstract}
This paper presents a three-dimensional crack initiation analysis in a sidegrooved CT specimen. This is achieved with an endochronic damage model proposed recently by Chow and Chen $[1,2]$ and discretized for finite element analysis. The damage model enables the quantification of the progressive damage evolution which would not be otherwise possible using the conventional fracture mechanics analysis. By employing two separate damage failure criteria, the crack is predicted to initiate at a small distance from the sidegroove and the prediction agrees well with the experimental observation. A more uniform crack initiation across the crack-tip line is observed both experimentally and theoretically relative to the CT specimen without sidegrooving.
\end{abstract}

\section{Introduction}

In an earlier investigation, nonuniform crack initiation along the crack-tip front producing a tunneling phenomenon was observed experimentally in CT specimens without sidegroove, [3]. The extent of tunneling increased with crack growth. The crack was predicted to first initiate at the middle of the crack-tip line for a CT specimen without sidegroove with the endochronic damage analysis [3]. From both experimental and numerical results, it was found that the specimen thickness had a definite influence on the stress state, damage evolution and the crack initiation load. These phenomena result from the nonuniform stress state across the thickness due to different deformation constraints.

In fracture toughness testing, the thickness of the test specimens should be large enough to ensure that the majority of the specimen thickness deforms in plane strain mode and the distribution of the stress state is uniform over most of the interior part. This is to ensure that maximum uniformity of the crack-tip profile can be achieved. In reality, one of the important factors influencing the crack initiation load is the stress state or deformation constraint at the crack tip. In standard fracture toughness test specimens, the stress state near and at the two side surfaces is in plane stress and approaches to plane strain towards the interior part of the specimen. There is therefore a transition region between the surface plane stress deformation mode and the interior plane strain deformation mode if the plane strain region exists. When the specimen thickness is large enough, the majority of the interior of the thickness is in the plane strain deformation mode, thus producing uniform crack propagation over most of the interior part. If the stress state could be created to be almost uniform along the crack-tip profile in some other ways, then uniform crack initiation across the thickness could also be obtained without requiring the use of larger specimen thickness. DeLorenzi and Shih [4] and Shih et al. [5] studied the fracture behavior of sidegrooved fracture specimens. It was found that the unifrom crack propagation profile can be obtained with a sidegrooved specimen and the crack initiation load in plane strain condition can also be obtained with a smaller specimen with sidegroove. 
Obviously the effects of sidegrooves are localized, so that some associated problems should be discussed when global parameters such as $J$ are employed to analyze the fracture behavior. Firstly $J$ is defined in a plane perpendicular to the crack front line. For a sidegrooved specimen, the deformation mode is different in the plane where $J$ is defined. In the crack extension line where the deformation in the thickness direction is constrained by the bulk material above and below the sidegroove, the deformation mode is quite different from that in other parts remote from the sidegroove. Actually, the $J$ 's applicability in fracture analysis depends on the $J$-dominant fields in the crack-tip regions. This could be achieved for power law hardening material when certain size requirements of fracture specimens without sidegroove are satisfied. But for the CT specimen with sidegroove, especially at the close proximity of the sidegroove where the deformation constraint change abruptly at crack initiation, the $J$-dominance in this case becomes questionable. Another important phenomenon which is not considered in the conventional fracture mechanics based analysis, is the damage development at the crack tip that can result in considerable stress redistribution and its associated stiffness change.

In this paper, a CT specimen with sidegroove is analyzed using an endochronic damage model. The material used was 2024-T351 aluminum alloy of thickness $12.7 \mathrm{~mm}$. The constitutive equations to describe the material behavior incorporate the endochronic theory of plasticity coupled with anisotropic damage. A three-dimensional finite element program employing the constitutive equations has been developed to evaluate distributions of the stress, strain and damage, etc. As the damage evolution and damage effects are included in the analysis, the progressive material deterioration and failure process in the crack tip are obtained, which would not otherwise be possible using the conventional fracture mechanics analysis.

\section{An endochronic damage theory}

The constitutive equations used in this study are based on an endochronic theory of plasticity coupled with anisotropic damage. The plastic damage model introduces the effective stress and the effective strain. The intrinsic time is defined in the effective plastic strain space as $[1,2]$

$$
\begin{aligned}
\mathrm{d} z & =\frac{\mathrm{d} \zeta}{f(\zeta)}, \\
\mathrm{d} \zeta & =\left(d \widetilde{\mathbf{e}}^{p}: d \widetilde{\mathbf{e}}^{p}\right)^{1 / 2},
\end{aligned}
$$

where $f(\zeta)$ is the hardening function, which is chosen as $1+\beta \zeta$ where $\beta$ is a material constant. With the introduction of yielding surface, the incremental elastoplastic stress-strain relationship is $[3,6,7,8]$

$$
\begin{aligned}
\mathrm{d} \widetilde{\boldsymbol{\sigma}} & =2 \mu_{0}\left(\mathrm{~d} \widetilde{\boldsymbol{\varepsilon}}-\mathrm{d} \widetilde{\varepsilon}^{p}\right)+\lambda_{0}(\mathbf{I}: \mathrm{d} \widetilde{\boldsymbol{\varepsilon}}) \mathbf{I} \\
& =2 \mu_{0} \mathrm{~d} \widetilde{\boldsymbol{\varepsilon}}+\lambda_{0}(\mathbf{I}: \mathrm{d} \widetilde{\boldsymbol{\varepsilon}}) \boldsymbol{I}-\frac{2 \mu_{0}(\widetilde{\mathbf{S}}-\mathbf{r})\langle(\widetilde{\mathbf{S}}-\mathbf{r}): \mathrm{d} \widetilde{\varepsilon})}{C\left(S_{y}^{0}\right)^{2} f^{2}(\zeta)},
\end{aligned}
$$

where

$$
C=1+\rho_{1}(0)+\frac{(\widetilde{\mathbf{S}}-\mathbf{r}): \mathbf{h}^{*}}{S_{y}^{0} f^{2}(\zeta)}+\frac{S_{y}^{0} f^{\prime}}{2 \mu_{0}} \quad \text { and }
$$




$$
\begin{aligned}
& \mathbf{h}^{*}=\int_{0}^{z} \frac{\mathrm{d} \rho_{1}\left(z-z^{\prime}\right)}{\mathrm{d} z} \frac{\mathrm{d} \widetilde{\mathbf{e}}^{p}}{\mathrm{~d} z^{\prime}} \mathrm{d} z^{\prime} \quad \text { and } \\
& \langle a\rangle=a \quad \text { if } a>0, \quad\langle a\rangle=0 \quad \text { if } a \leqslant 0 .
\end{aligned}
$$

In the above equations, $\sim$ over a variable denotes its effective counterpart, $\widetilde{\mathbf{S}}$ is the deviatoric effective stress which is defined as $\widetilde{\boldsymbol{\sigma}}-\left(\widetilde{\sigma}_{i i} / 3\right) \mathbf{1}$ and $\widetilde{\mathbf{r}}$ is the 'back stress' defined as

$$
\widetilde{\mathbf{r}}=2 \mu_{0} \int_{0}^{z} \rho_{1}\left(z-z^{\prime}\right) \frac{\mathrm{de}^{p}}{\mathrm{~d} z^{\prime}} \mathrm{d} z^{\prime}
$$

As plastic deformation and stress state play two important roles in ductile damage evolution $[9,10,11]$, a new intrinsic time scale for ductile damage evolution is introduced as

$$
\mathrm{d} z_{d}=\frac{f_{R}(R) \mathrm{d} \zeta}{f_{d}(\zeta)}
$$

where $f_{d}(\zeta)$ is the hardening function and $f_{R}(R)$ represents the effects of stress state on ductile damage evolution. Because ductile damage evolution is closely related to the effective plastic deformation and $\zeta$ is a measure of effective plastic deformation, $\zeta$ is included in the definition of $z_{d}$. The hardening function $f_{d}(\zeta)$ is chosen as $1+\beta_{d} \zeta$, where $\beta_{d}$ is a material constant. The effect of stress triaxiality on damage evolution is introduced with $f_{R}(R)$, which is chosen in the form of $\exp \left(1.5 \widetilde{\sigma}_{m} / \widetilde{\sigma}_{\text {eq }}\right) . \widetilde{\sigma}_{m}$ is the effective hydrostatic stress defined as $\widetilde{\sigma}_{i i} / 3$ and $\widetilde{\sigma}_{\text {eq }}$ is the effective equivalent stress defined as $\left(\frac{3}{2} \widetilde{\mathbf{S}}: \widetilde{\mathbf{S}}\right)^{1 / 2}$. The damage evolution equation is obtained from the orthogonality rule with newly defined intrinsic time and damage dissipation 'power' $\Phi=\left(\frac{1}{2} \mathbf{Y}: \mathbf{J}: \mathbf{Y}\right)^{1 / 2}[1]$. Through the orthogonality rule, the damage evolution equation is derived as $[3,12]$

$$
\frac{\mathrm{d} \mathbf{D}}{\mathrm{d} z_{d}}=\lambda_{d} \frac{\mathbf{J}: \mathbf{Y}}{2\left(\frac{1}{2} \mathbf{Y}: \mathbf{J}: \mathbf{Y}\right)^{1 / 2}} H\left(z_{d}-z_{d}^{0}\right),
$$

where

$$
H(a)=1 \quad \text { for } a>0, \quad H(a)=0 \quad \text { for } a \leqslant 0
$$

and

$$
\lambda_{d}=\left\{\begin{array}{l}
1 \text { when } \Phi=\Phi_{\max } \text { and } \frac{\partial \Phi}{\partial \mathbf{Y}}: \mathrm{d} \mathbf{Y}>0 \\
0 \text { when } \Phi<\Phi_{\max } \text { or } \Phi=\Phi_{\max } \text { and } \frac{\partial \Phi}{\partial \mathbf{Y}}: \mathrm{d} \mathbf{Y} \leqslant 0
\end{array}\right.
$$

\section{Experimental investigation}

The geometry of a CT specimen with sidegroove is shown in Figure 1. The fatigue precracking was conducted on an Amsler Vibrophore 10T high frequency fatigue testing machine. The precracking fatigue load chosen is small enough to ensure that no significant residual plastic deformation exists at the crack tip after the fatigue precracking. The tension tests were 

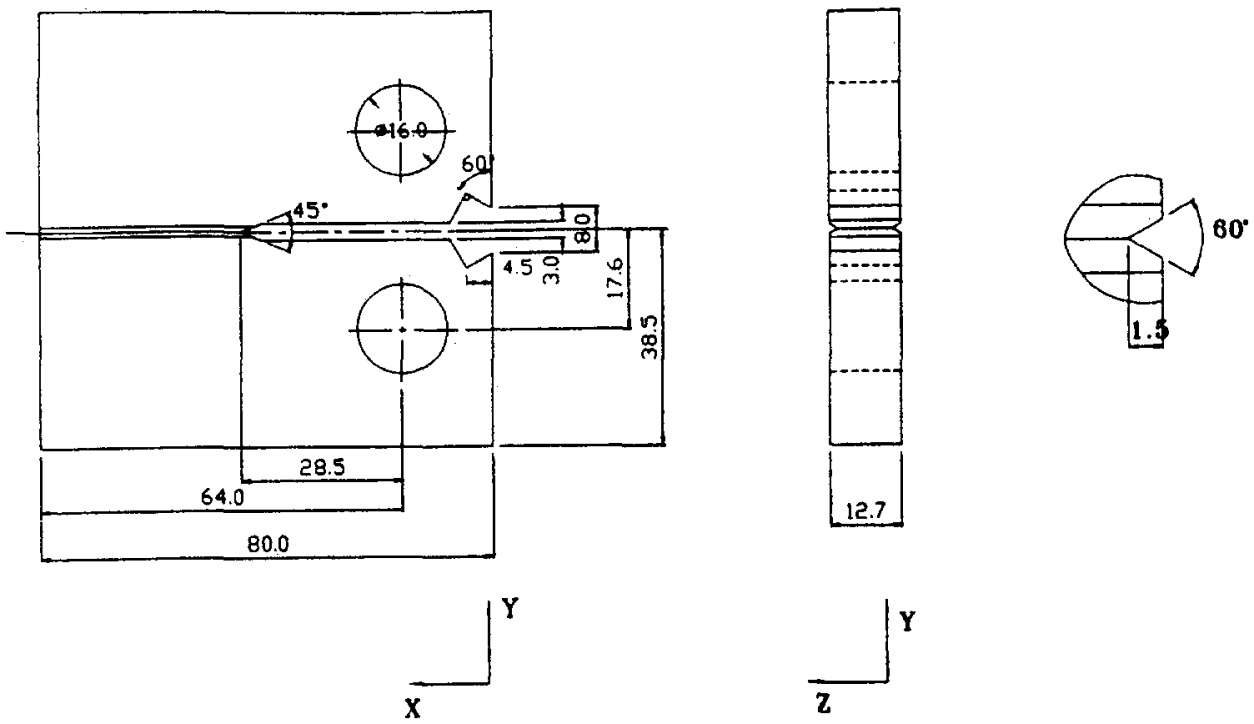

Figure 1. Geometry of sidegrooved CT specimen.
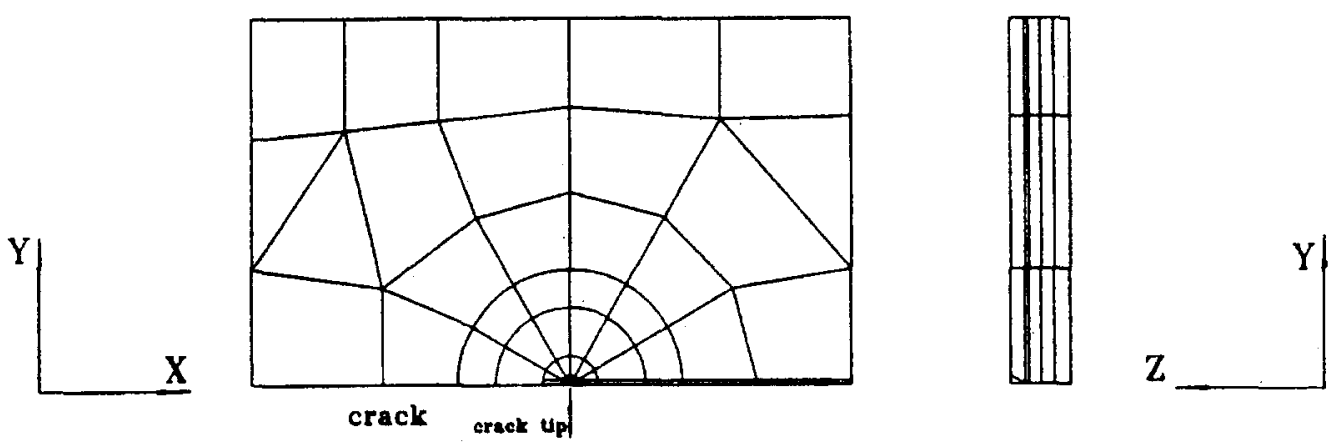

Figure 2. 3-D finite element mesh of sidegrooved CT specimen.

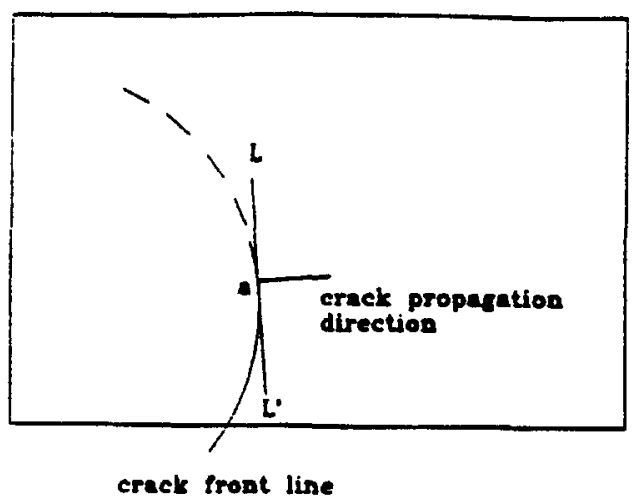

Figure 3. Schematic definition of the plane perpendicular to the crack front line. 


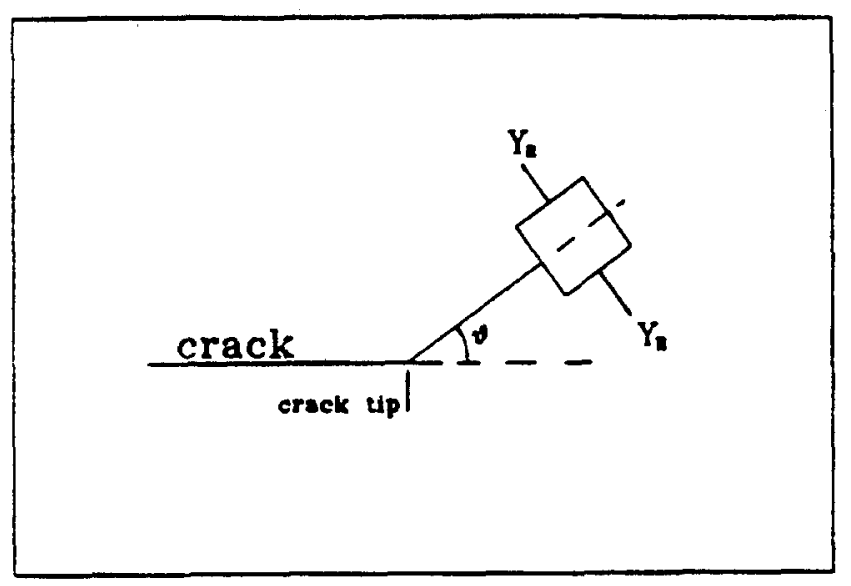

Figure 4. Definition of $Y_{R}$ at the crack tip.

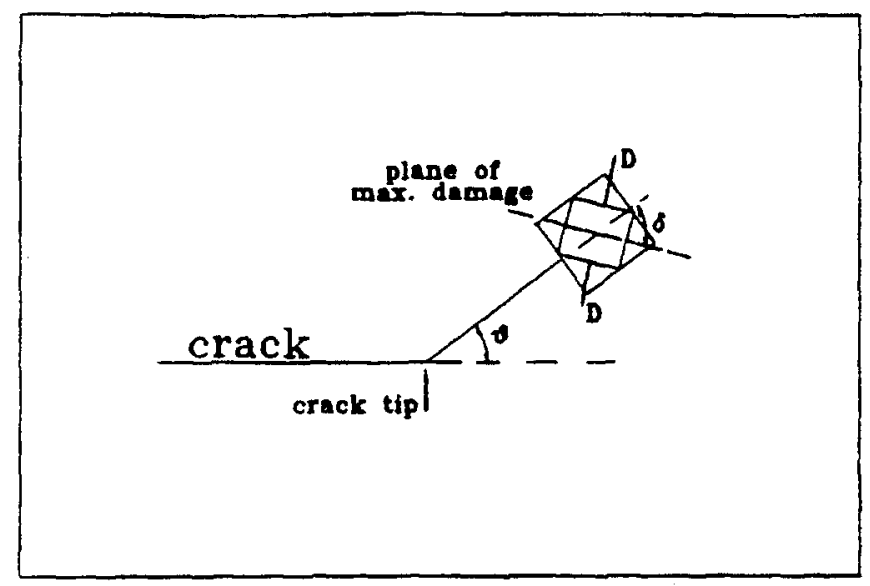

Figure 5. Definition of $\delta$ at the crack tip.

conducted on a universal 10T MTS testing machine. The specimens were loaded to different loads after crack initiation, so that different crack extensions were produced. After heat tinting, the specimens were reloaded to failure. The load $(P)$-crack extension $(\Delta a)$ relationship was obtained where $\Delta a$ was defined as the crack propagation area divided by the specimen thickness. From the $P-\Delta a$ data, the crack initiation load of $12.30 \mathrm{kN}$ was obtained.

From the crack propagation profile obtained from the fracture surface after the heat tinting, a crack initiated at a very small distance from the sidegroove. In the interior part between the sidegrooves, the crack initiation and propagation profile was quite uniform, although the crack propagated a little further at a small distance from ihe sidegroove notch than in the middle part, which is the first crack initiation point at the crack tip. During the crack propagation process, the nonuniformity did not increase substantially. This phenomenon is very different from that in a CT specimen without sidegrooving, where the nonuniformity increased considerably during the continued loading process [3]. 

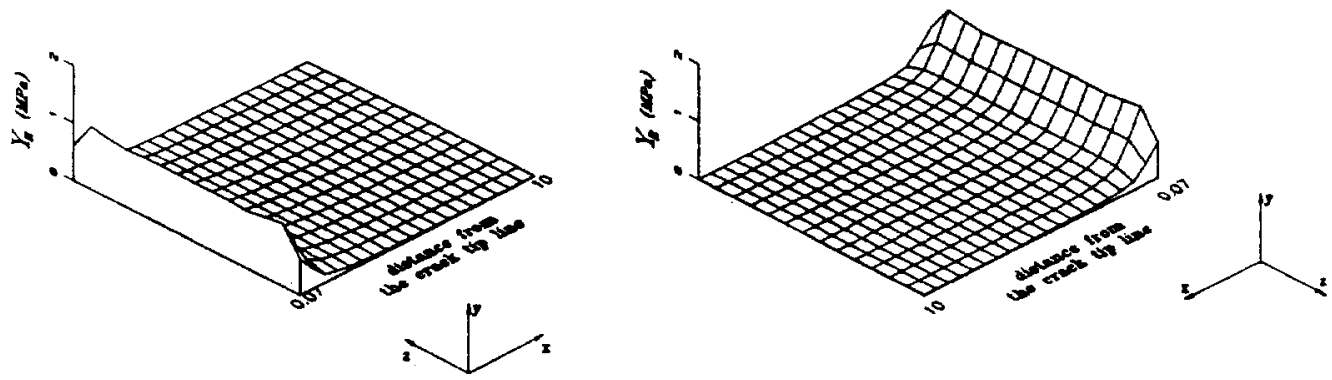

Figure 6. Distribution of $Y_{R}$ over the crack extension plane of sidegrooved specimen at the load of $5.75 \mathrm{kN}$.
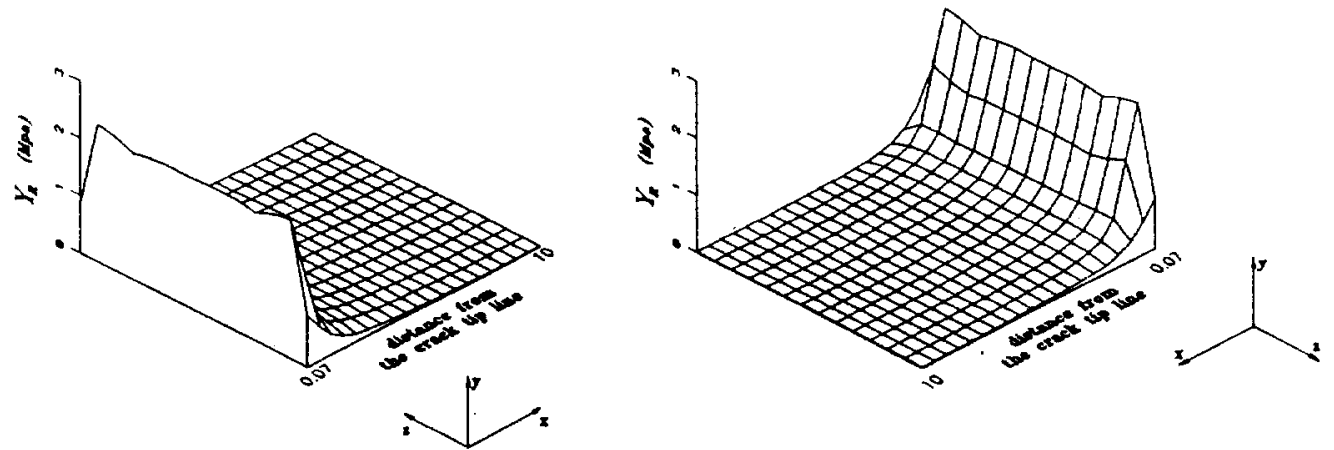

Figure 7. Distribution of $Y_{R}$ over the crack extension plane of sidegrooved specimen at the load of $9.55 \mathrm{kN}$.

\section{Finite element mesh and numerical analysis procedures}

Because of the symmetry of the specimen and the applied load, only one quarter of the specimen needs to be analyzed. The three-dimensional finite element mesh is shown in Figure 2. The boundary conditions of the symmetric plane are treated in the following way. The displacements of all the nodes in the middle plane $(x-y$ plane) are restrained along $z$ direction and the displacements of all the nodes on $x-z$ plane are restrained along $y$-direction, except in the cracked region.

The procedure in formulating the finite element analysis with damage is similar in principle to the conventional FEM analysis. The endochronic constitutive equations coupled with damage are similar in form to the conventional elasto-plastic constitutive equations with isotropic-nonlinear kinematic hardening. The element stiffness matrix $[K]$ is a function of transformation $[B]$ and stress-strain matrix $[C]$ defined as

$$
[K]=\int_{v}[B]^{T}[C][B] \mathrm{d} V
$$

where $[C]$ is related to the material properties while $[B]$ is associated with the element chosen in the analysis. Therefore only $[C]$ needs to be modified when damage effects are taken into account. The effective elastic relation may be written in matrix form as

$$
\{\mathrm{d} \widetilde{\sigma}\}=\left[C^{e}\right]\left\{\mathrm{d} \widetilde{\varepsilon}^{e}\right\} .
$$

With the endochronic constitutive equation coupled with damage (3), the effective stress-strain relation is obtained from (8)

$$
\{\mathrm{d} \widetilde{\sigma}\}=\left[C^{*}\right]\{\mathrm{d} \widetilde{\varepsilon}\},
$$



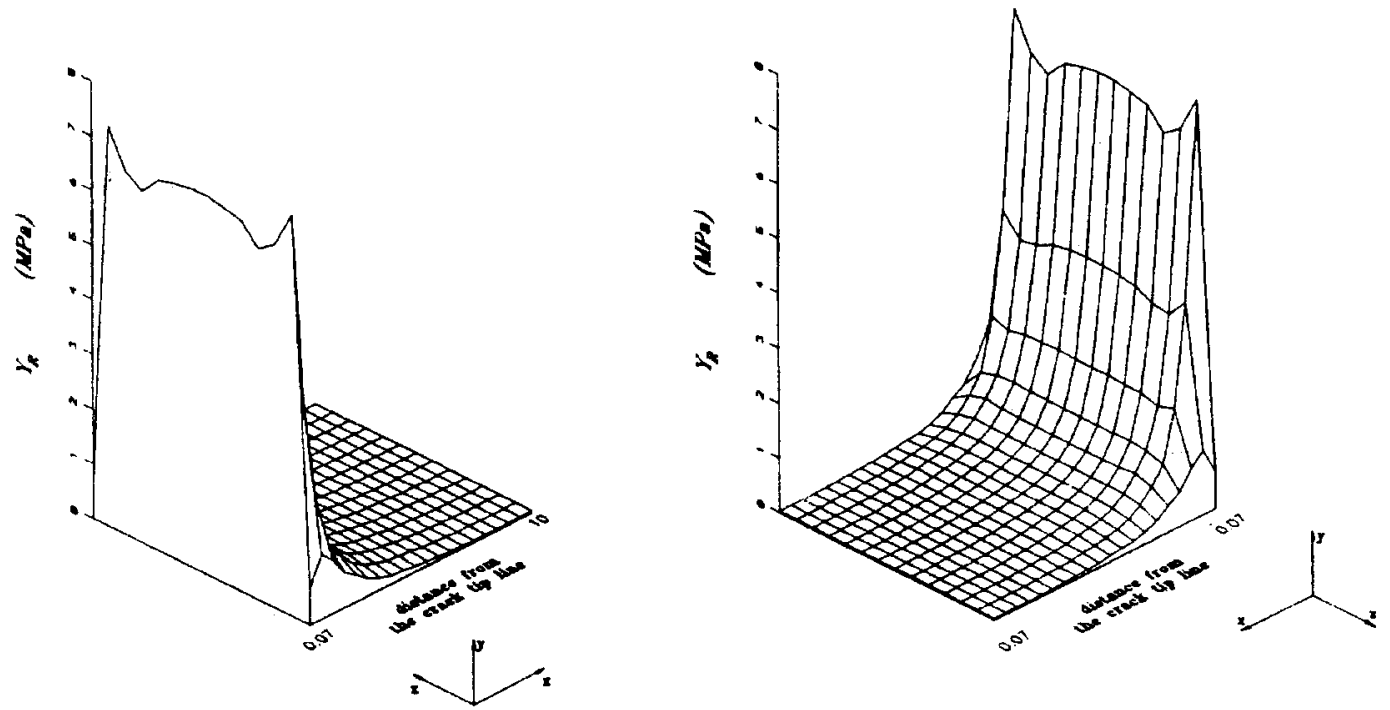

Figure 8. Distribution of $Y_{R}$ over the crack extension plane of sidegrooved specimen at the predicted crack initiation load of $11.96 \mathrm{kN}$ with the $Y_{R}$ criterion.

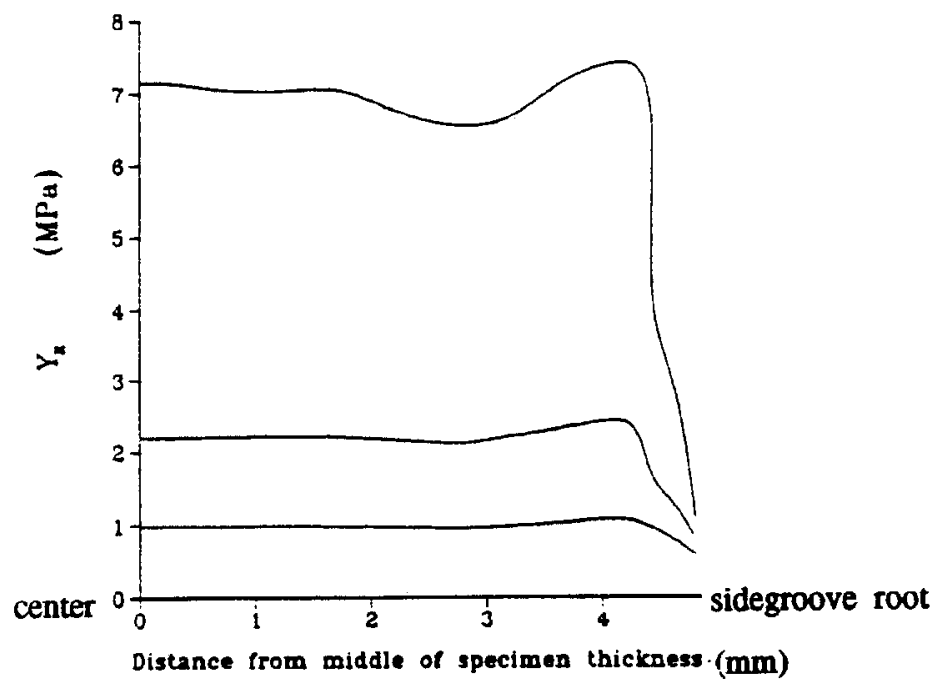

Figure 9. Distribution of $Y_{R}$ at a constant distance of $0.07 \mathrm{~mm}$ from the crack-tip line.

where

$$
\left[C^{*}\right]=\left[C^{e}\right]-2 \mu_{0} \frac{\{\hat{S}\}\{\hat{S}\}}{C\left(S_{y}^{0}\right)^{2} f^{2}(\zeta)}
$$

and $\hat{S}$ denotes $(\widetilde{\mathbf{S}}-\mathbf{r})$. Since $\left[C^{*}\right]$ in (9) is effective stress-strain matrix, it is desirable to transform it to the conventional stress-strain matrix for the evaluation of the element stiffness matrix. Equation (9) may thus be deduced as [3]

$$
\{\mathrm{d} \widetilde{\sigma}\}=\left[\widetilde{C}^{*}\right]\{\mathrm{d} \varepsilon\},
$$




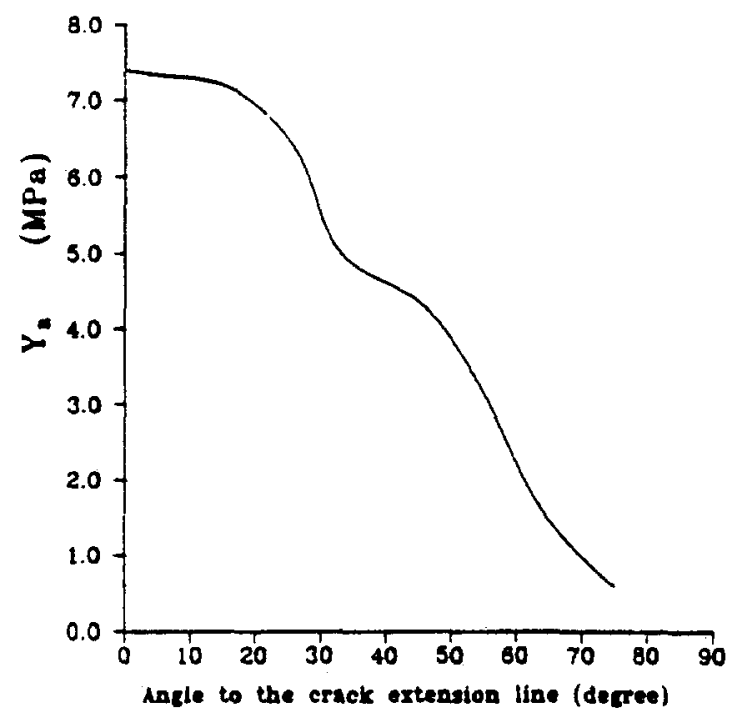

Figure 10. Angular distribution of $Y_{R}$ in the crack tip of the plane where crack initiates.
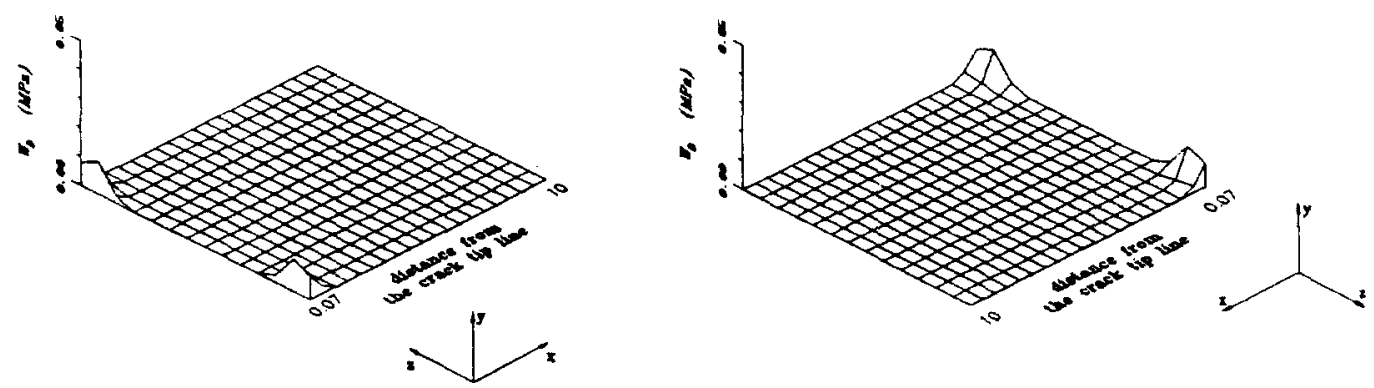

Figure 11. Distribution of $W_{D}$ over the crack extension plane of sidegrooved specimen at the load of $9.55 \mathrm{kN}$.

where

$$
\begin{aligned}
& {\left[\tilde{C}^{*}\right]=[M]^{-1}([I]+[Q])\left([I]-\left[C^{*}\right][P]\right)^{-1}\left[C^{*}\right][M]^{T,-1}} \\
& {[Q]=\frac{B_{0}}{f_{d}(\zeta)} f_{R}(R)[M] \frac{\partial[M]^{-1}}{\partial\{D\}^{T}} \frac{\partial \Phi}{\partial\{Y\}^{T}}[M]\{\sigma\}\{\hat{S}\}^{T}} \\
& {[P]=\frac{B_{0}}{f_{d}(\zeta)} f_{R}(R) \frac{\partial[M]^{T,-1}}{\partial\{D\}^{T}} \frac{\partial \Phi}{\partial\{Y\}^{T}}\{\varepsilon\}\{\hat{S}\}^{T}}
\end{aligned}
$$

and

$$
B_{0}=\frac{1}{2 \mu_{0}(C-1) S_{y}^{0} f(\zeta)}
$$

As the damage effects are incorporated in the finite element analysis, the stiffness change due to damage and subsequent stress redistribution can be manifested. The step-by-step 

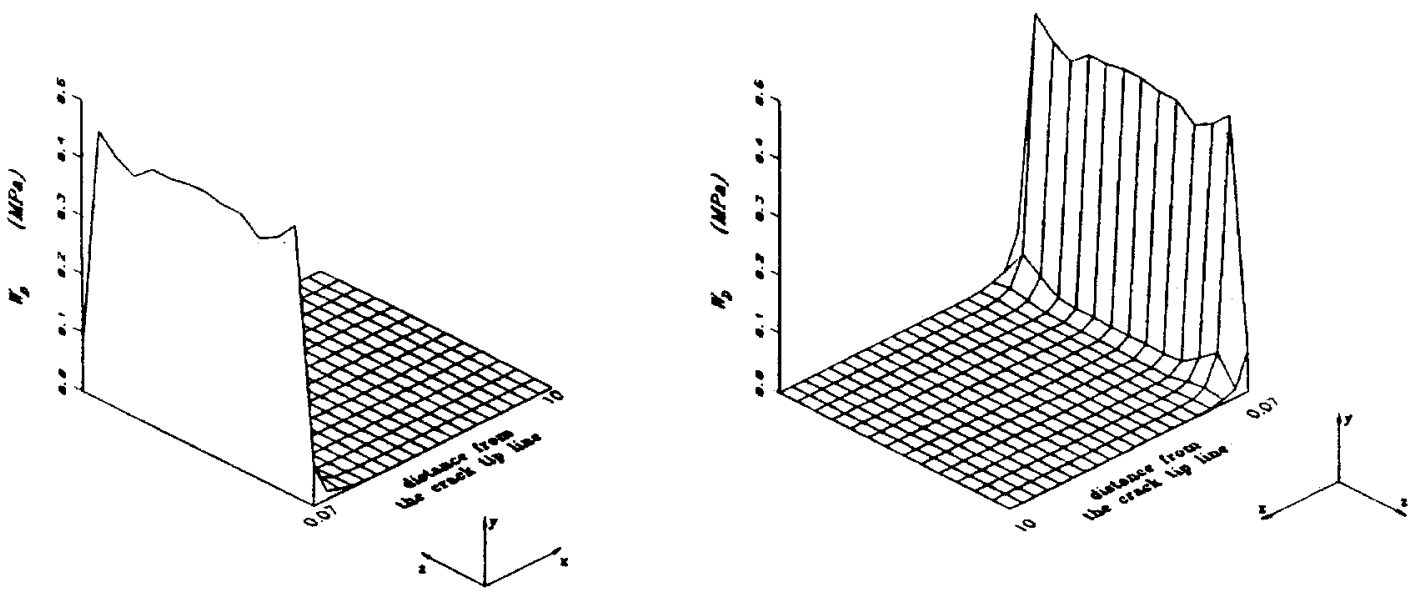

Figure 12. Distribution of $W_{D}$ over the crack extension plane of sidegrooved specimen at the predicted crack initiation load of $11.87 \mathrm{kN}$ with the $W_{D}$ criterion.

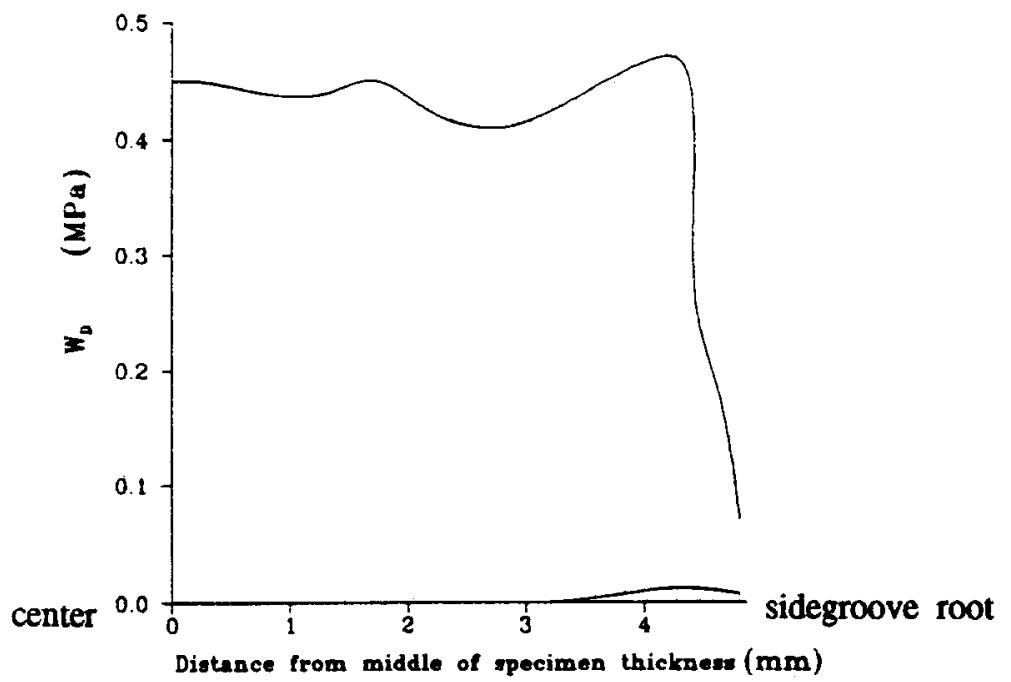

Figure 13. Distribution of $W_{D}$ at a constant distance of $0.07 \mathrm{~mm}$ from the crack-tip line.

incremental analysis scheme is employed because the material behavior is nonlinear. The first loading step is comparatively large just before the yielding takes place at the crack tip. This is followed by the incremental analysis with small loading steps until crack initiation along the crack-tip line.

The three-dimensional crack initiation criterion used in this study is defined in the following way. First, a plane perpendicular to the crack front line is assumed as shown in Figure $3 . Y_{R}$ is defined as the tangential component of damage strain energy release rate $\mathbf{Y}$ at a radical distance from the crack front line (Figure 4), where the crack will advance in the radial direction perpendicular to the crack front line. The $Y_{R}$ criterion assumes that the crack initiates, when $Y_{R}$ reaches its critical value, in the radial direction where $Y_{R}$ attains its maximum value at a characteristic distance from the crack tip. The critical value of $Y_{R}$ determined from the uniaxial tension test is $7.39 \mathrm{MPa}$. 


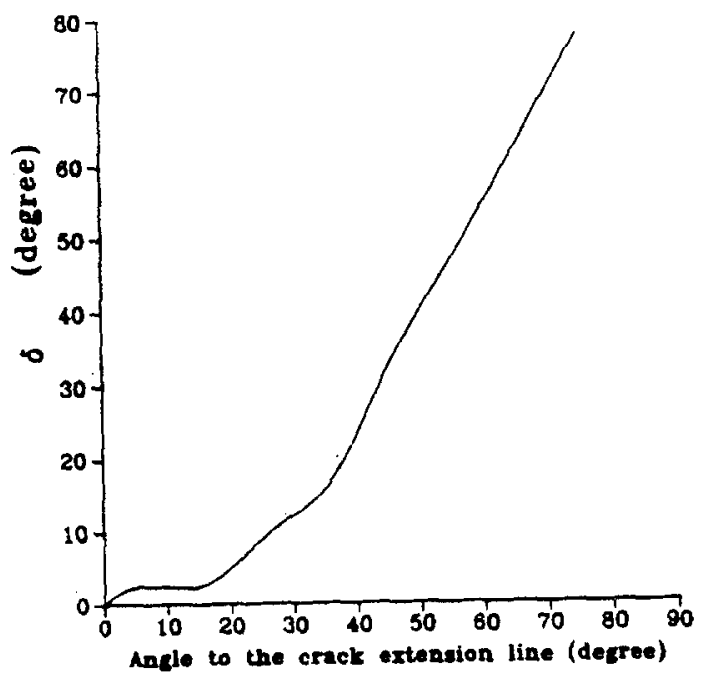

Figure 14. Angular distribution of $\delta$ in the crack tip of the plane where crack initiates.

As to the second criterion, $\delta$ is the angle between the radial line from the crack tip and the maximum damage plane as shown in Figure 5. This parameter is used to determine the crack initiation direction. The crack is assumed to initiate in the direction where $\delta$ is the minimum. When the angle of crack initiation direction is determined, the critical condition for the crack initiation along this direction is satisfied, when the damage dissipation energy $W_{D}$ defined as

$$
W_{D}=\int_{0}^{\zeta} \mathbf{Y}: \mathrm{d} \mathbf{D}
$$

reaches its critical value at a characteristic length from the crack-tip. The critical $W_{D}$ value determined from the uniaxial tension test is $0.46 \mathrm{MPa}$.

After the computation of the stress distribution in a cracked plate, the next step to predict the crack initiation load is to identify the critical location along the crack-tip line using the above-mentioned failure criteria of $Y_{R}$ and $W_{D}$ due to Chow and Chen [3]. After the critical location is identified, the crack initiation load and crack initiation direction can be readily determined in accordance with the crack initiation criteria.

\section{Discussion of numerical results}

The $Y_{R}$ (the component of $\mathbf{Y}$ perpendicular to the crack extension plane) distribution at the load of $5.75 \mathrm{kN}$ is shown in Figure 6. It is readily observed from the figure that $Y_{R}$ is constant over most of the interior across the thickness. Generally speaking, the variation of $Y_{R}$ across the whole thickness is quite small at the crack tip. The maximum $Y_{R}$ is located at a small distance from the sidegroove root at the crack tip. With increase in distance from the crack-tip line, $Y_{R}$ decreases very quickly to a very small value, and its variation across the thickness also decreases.

When the load increases to $9.55 \mathrm{kN}$ (Figure 7), the variation of $Y_{R}$ across the thickness in the interior part does not increase substantially although its magnitude increases considerably. In Figure 8 , the $Y_{R}$ distribution on the crack extension plane, at the predicted crack initiation load of $11.96 \mathrm{kN}$ with the $Y_{R}$ criterion, is shown. The maximum value is located at a small 

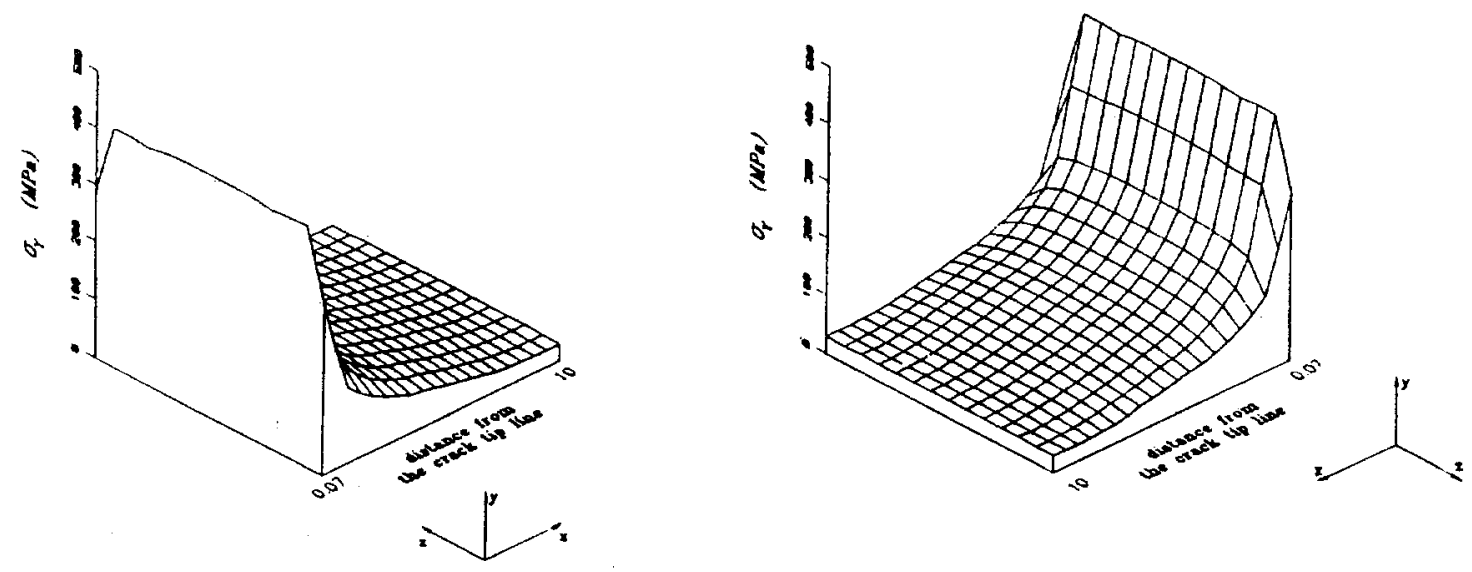

Figure 15. Distribution of $\sigma_{y}$ over the crack extension plane of sidegrooved specimen at the load of $5.75 \mathrm{kN}$.

distance from the sidegroove root. The distribution of $Y_{R}$ along the crack tip is quite uniform over most of the interior, compared with that in CT specimens without sidegrooving [3], but it decreases quickly in the region near the sidegroove notch. $Y_{R}$ decreases rapidly away from the crack tip.

The $Y_{R}$ distribution along the line at the distance of $0.07 \mathrm{~mm}$ ahead of the crack tip in the crack extension plane at different loads is shown in Figure 9. At smaller applied loads, the variations of $Y_{R}$ in the thickness direction is quite uniform over most of the interior, increases slightly and then decreases, when approaching the notch root. At a larger load of $11.96 \mathrm{kN}$, the variation of $Y_{R}$ does not increase substantially in the interior, but does show a marked increase close to the sidegroove root. The maximum value of $Y_{R}$ is attained at a small distance from the sidegroove root.

The angular distribution of $Y_{R}$ at $r=0.07 \mathrm{~mm}$ from the crack tip in the plane perpendicular to the crack initiation at the crack tip, is shown in Figure 10. It can be readily observed from the figure that the maximum value of $Y_{R}$ is in the direction of crack extension, indicating that the crack will initiate along the crack extension direction according to the $Y_{R}$ criterion.

As to the damage distribution obtained based on the $W_{D}$ criterion, the $W_{D}$ distribution over the crack extension plane at the load of $9.55 \mathrm{kN}$ is shown in Figure 11. The non-zero $W_{D}$ distribution is localized in two corner areas near the sidegroove at the crack tip. This is because the damage first develops favorably there. The maximum value of $W_{D}$ is located at a small distance from the sidegroove at the crack tip, and attains its critical value when the load increases to the predicted crack initiation load of $11.87 \mathrm{kN}$. The $W_{D}$ distribution in the crack extension plane at the load of $11.87 \mathrm{kN}$ is shown in Figure 12. $W_{D}$ displays almost uniformly across the thickness in most interior parts of the specimen, except in the small region near the sidegroove where the variation of $W_{D}$ is comparatively large. $W_{D}$ decreases rapidly with increase in distance from the crack tip, and the distribution across the thickness is more uniform.

The $W_{D}$ distribution at different load levels along the line at $r=0.07 \mathrm{~mm}$ ahead of the crack tip is shown in Figure 13. $W_{D}$ first initiates close to the sidegroove area. Its maximum value is located at a small distance from the sidegroove notch and it is zero in the interior. As the load increases, the distribution of $W_{D}$ in the interior part is quite uniform and only drops 

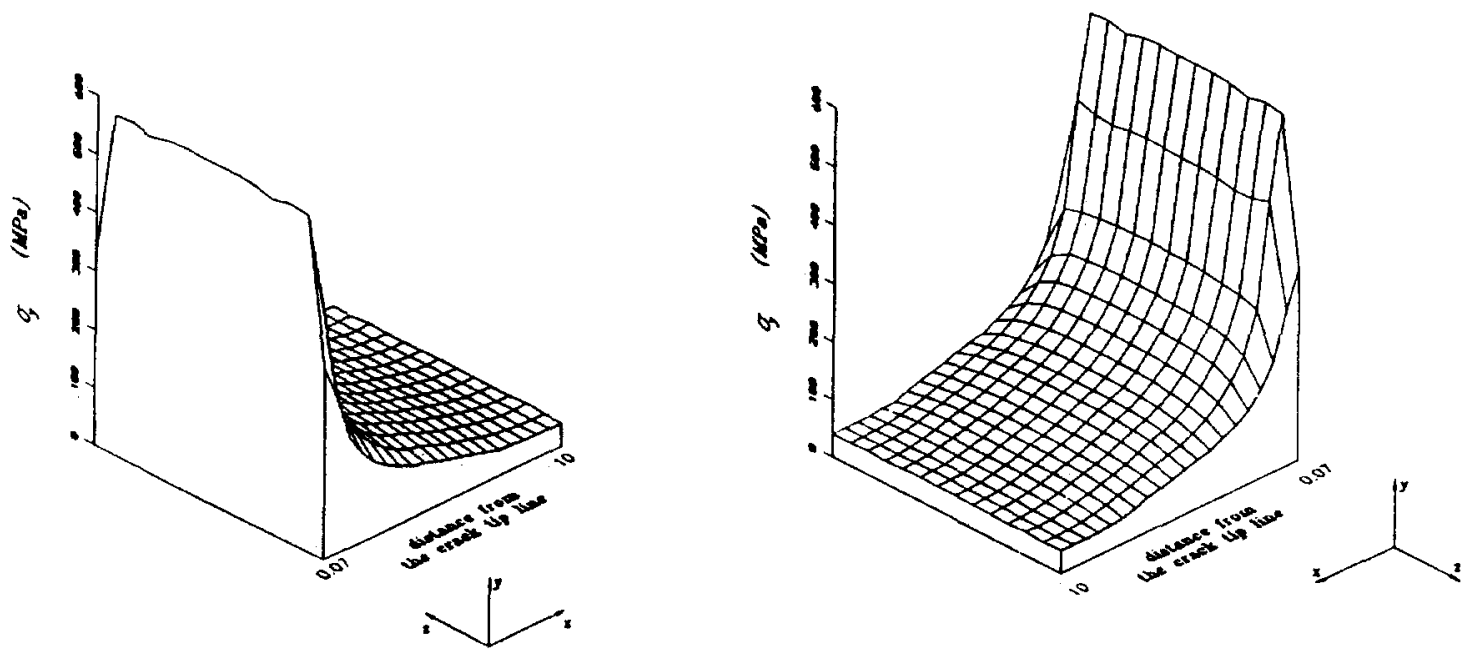

Figure 16. Distribution of $\sigma_{y}$ over the crack extension plane of sidegrooved specimen at the load of $9.55 \mathrm{kN}$.
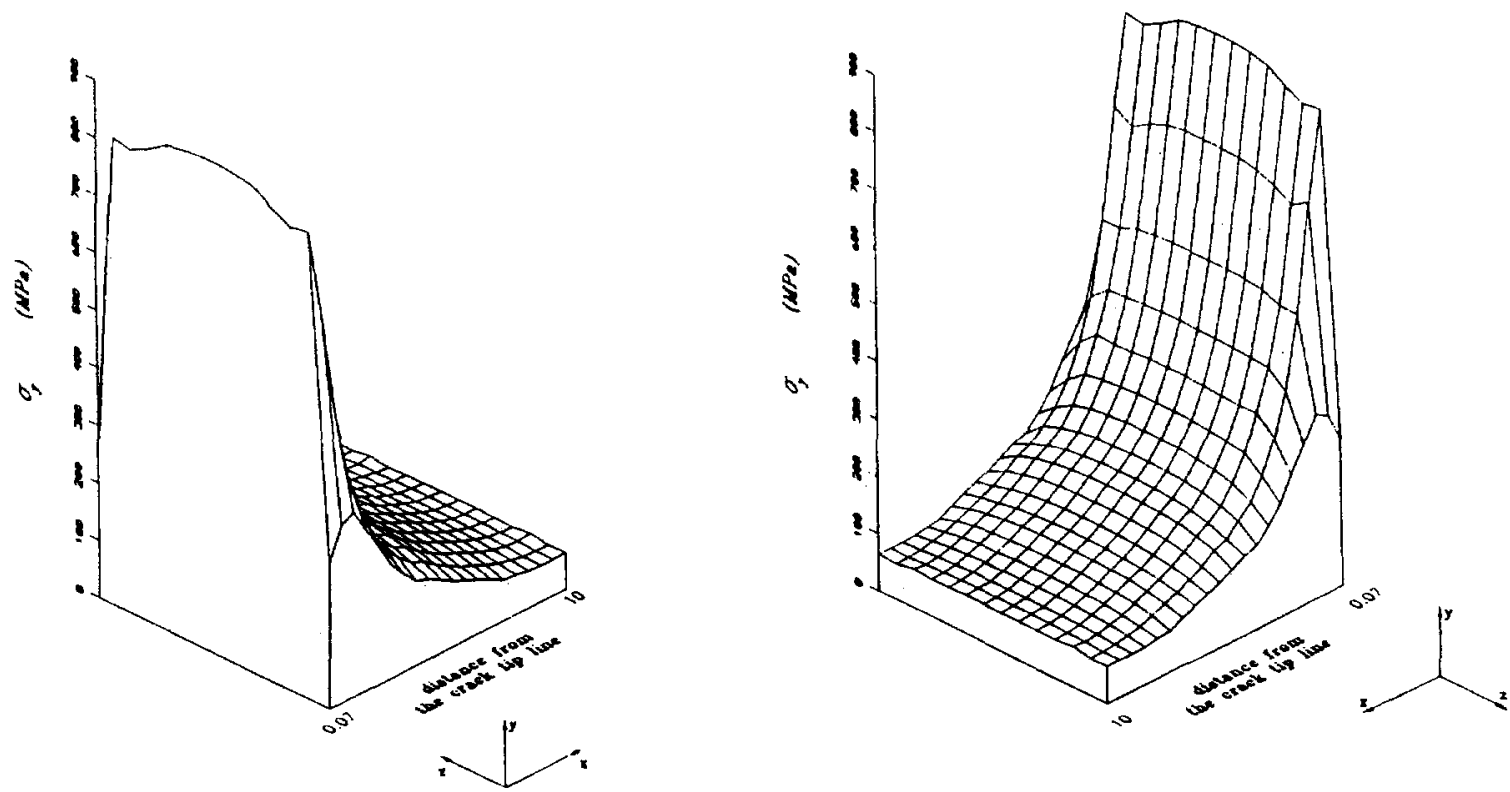

Figure 17. Distribution of $\sigma_{y}$ over the crack extension plane of sidegrooved specimen at the predicted crack initiation load of $11.96 \mathrm{kN}$ with the $Y_{R}$ criterion.

rapidly in the region of the sidegroove notch. The maximum value of $W_{D}$ is situated at a small distance from the sidegroove root.

The angular distribution of $\delta$ at $r=0.07 \mathrm{~mm}$ in the plane perpendicular to the crack line at crack initiation is shown in Figure 14. The minimum value of $\delta$ is 0 located in the crack extension direction. This is the crack initiation direction according to the $\delta$ criterion.

It may be concluded from the above, that more uniform distributions in terms of the damage parameters $Y_{R}$ and $W_{D}$ employed in the crack initiation criteria, can be achieved. This is due to the existence of the sidegroove, which constrains the deformation in the thickness direction 

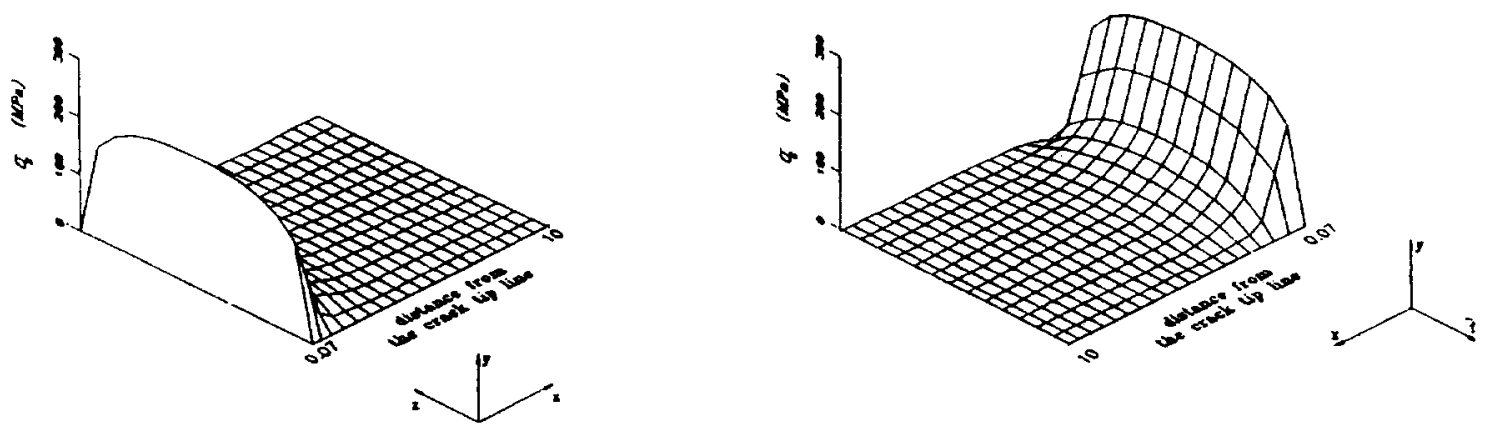

Figure 18. Distribution of $\sigma_{z}$ over the crack extension plane of sidegrooved specimen at the load of $5.75 \mathrm{kN}$.
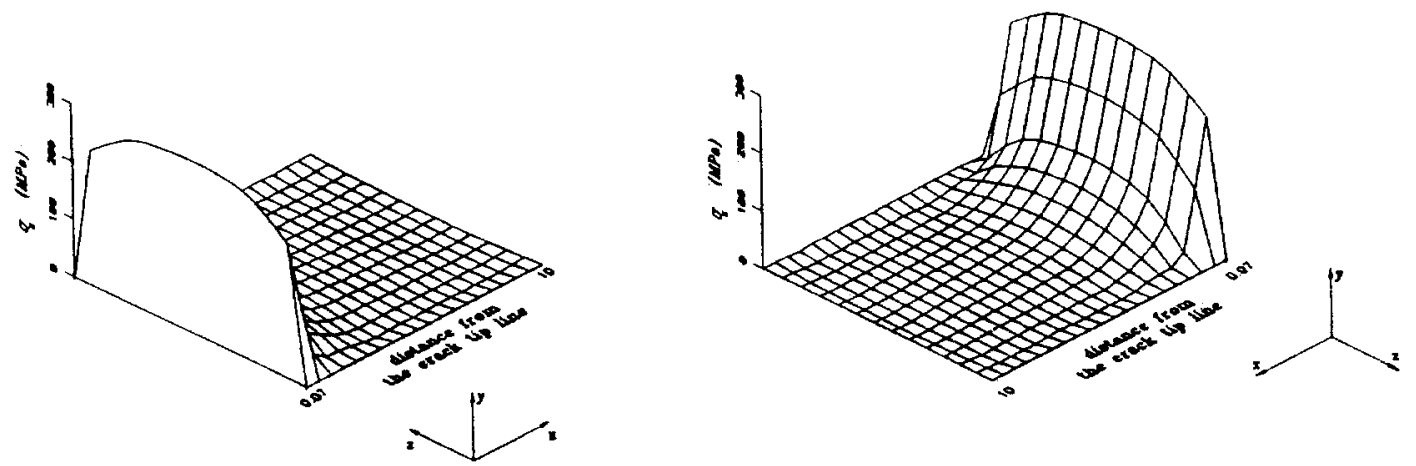

Figure 19. Distribution of $\sigma_{z}$ over the crack extension plane of sidegrooved specimen at the load of $9.55 \mathrm{kN}$.

of the materials ahead of the crack tip. As damage development strongly depends on the stress state, the stress distribution at different load levels will be discussed next.

The $\sigma_{y}$ distributions over the crack extension plane at the applied loads of $5.75 \mathrm{kN}, 9.55 \mathrm{kN}$ and $11.96 \mathrm{kN}$ are shown in Figures 15, 16 and 17, respectively. The variation of $\sigma_{y}$ across the thickness is very small even at the crack tip. It remains almost constant over most of the thickness, and only decreases in the region at the sidegroove. With increase in applied load, the variation of $\sigma_{y}$ in the thickness direction increases slightly, but it is almost negligible compared with that of CT specimens without sidegrooving [3]. This phenomenon demonstrates the full effect of sidegrooving and its usefulness for testing.

In Figures 18,19 and 20, the $\sigma_{z}$ distributions at the loads of $5.75 \mathrm{kN}, 9.55 \mathrm{kN}$ and $11.96 \mathrm{kN}$, are shown respectively. The distributions of $\sigma_{z}$ in the interior thickness are seen to be uniform and not strongly affected by increases in applied load.

Stress traixiality distributions at the different load levels are shown in Figures 21, 22 and 23, respectively. The variation of stress triaxiality in the interior of the specimen does not increase, but actually decreases a little as the applied load increases. This indicates the distribution of stress triaxiality tends to be more uniform in the interior, with increase in applied load, but its variation near the sidegroove root increases considerably during the loading process.

From both the $Y_{R}$ and $W_{D}$ distributions, there is a small region near the sidegroove where $Y_{R}$ and $W_{D}$ decrease rapidly when approaching the root of the sidegroove. This may be explained in the following way. In the region near the sidegroove root, the stress state is influenced by the free surface at the sidegroove root, although the large bulk material above and below the sidegroove, restricts the deformation in the thickness direction of material 

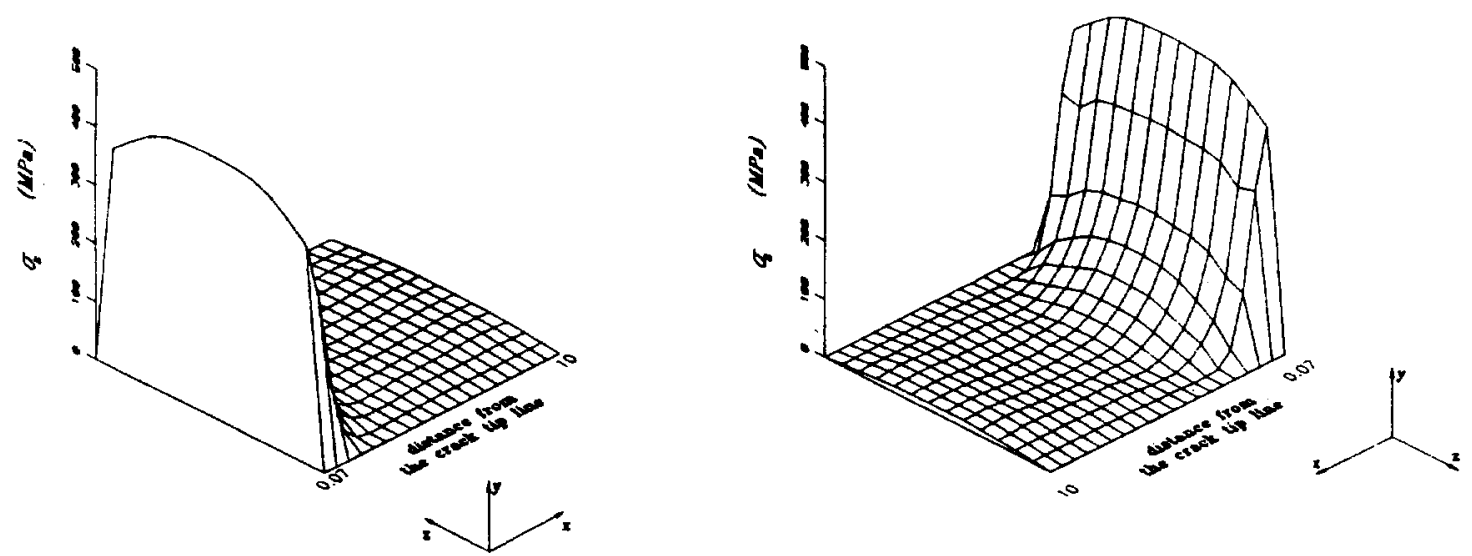

Figure 20. Distribution of $\sigma_{z}$ over the crack extension plane of sidegrooved specimen at the predicted crack initiation load of $11.96 \mathrm{kN}$ with the $Y_{R}$ criterion.
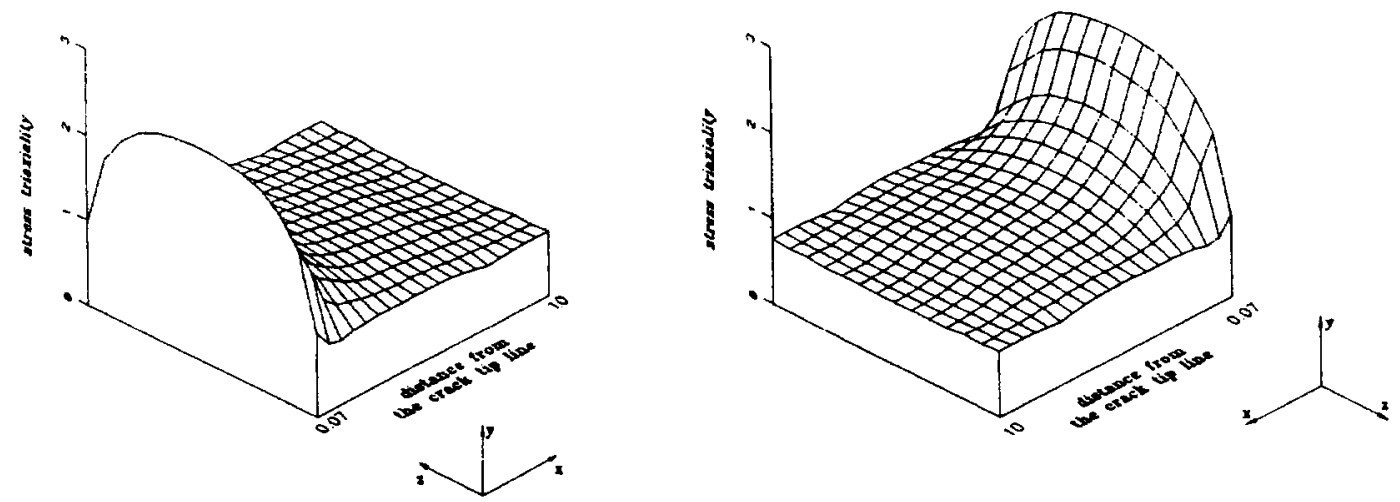

Figure 21. Distribution of stress traxiality over the crack extension plane of sidegrooved specimen at the load of $5.75 \mathrm{kN}$.

elements in the interior. Therefore the stress triaxiality drops quickly at the sidegroove root. Consequently, the damage development rate is comparatively small in this region, causing $Y_{R}$ and $W_{D}$ to decrease quickly.

The large bulk material above and below the sidegroove constraining the deformation in the thickness direction, only affects the region at a small distance from the sidegroove root. Therefore, the deformation constraint is comparatively stable in the interior of the thickness, but decreases quickly at the sidegroove root due to the free boundary condition.

It is obvious that there are two distinct regions within the specimen thickness. One is a rapid transition region near the sidegroove root, the other is a more uniform region in the interior of the thickness, whose deformation is constrained by the bulk material above and below the sidegroove. This phenomenon is different from those in CT specimens without a sidegroove. In those specimens, the stress state in the transition zone changes progressively from the uniform interior region to the surface, so that $\sigma_{y}, \sigma_{z}$ and the stress triaxiality, change gradually to the plane stress state in the region close to the surface. But there is a distinctive transition point between the two regions decribed above in sidegrooved specimens. In the region of the sidegroove, the variation of $\sigma_{z}$ increases with increase in applied load, while the variation of $\sigma_{z}$ in the interior of thickness remains almost unchanged with the applied load, 

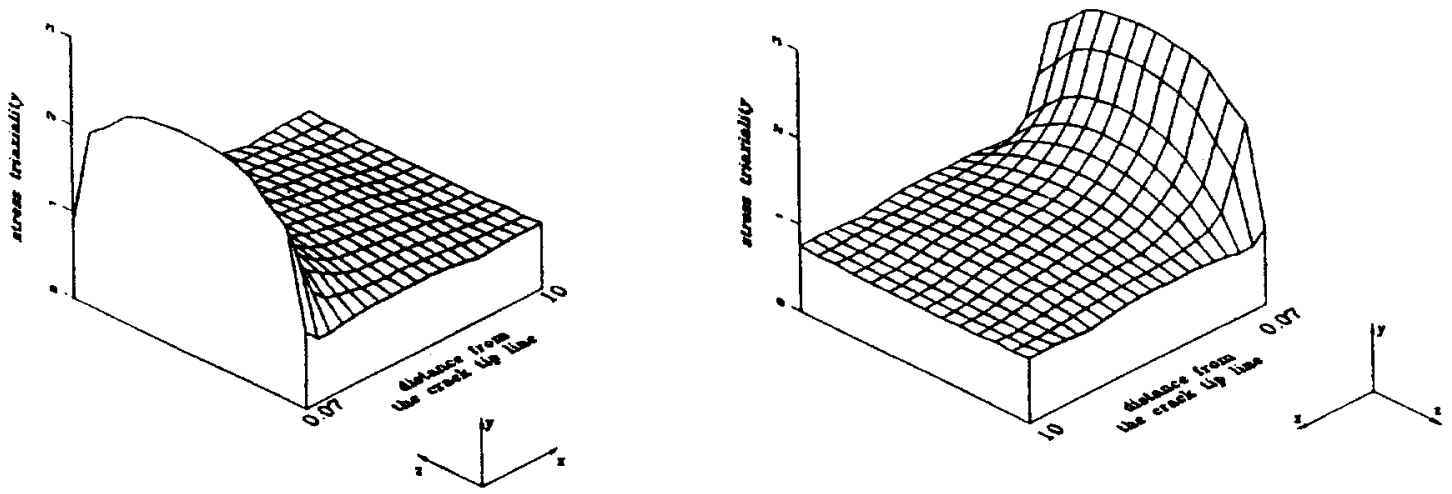

Figure 22. Distribution of stress triaxiality over the crack extension plane of sidegrooved specimen at the load of $9.55 \mathrm{kN}$.
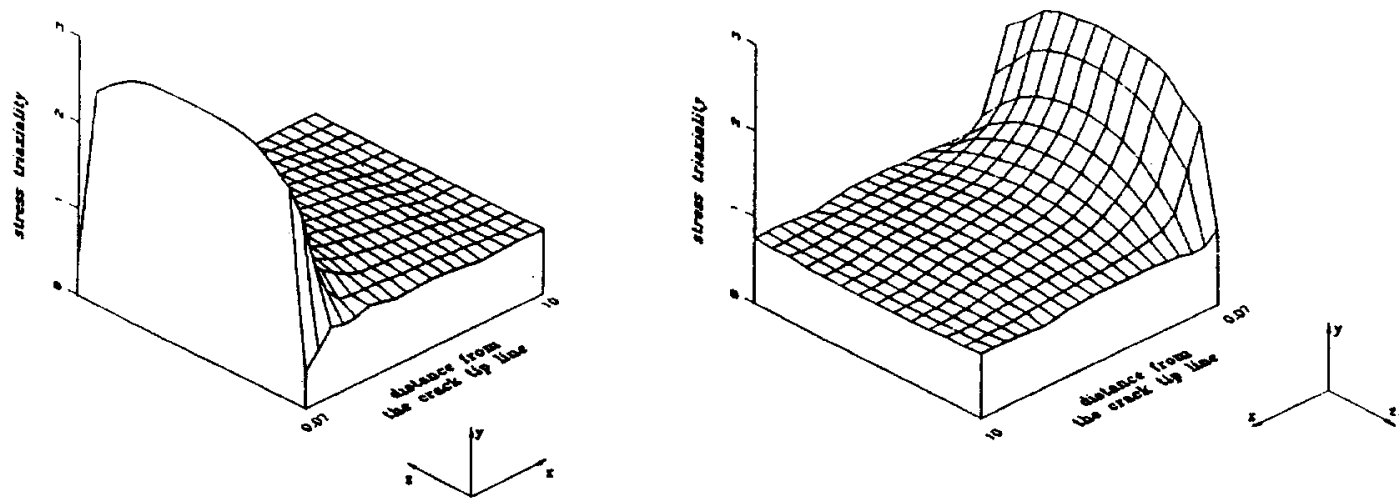

Figure 23. Distribution of stress triaxiality over the crack extension plane of sidegrooved specimen at the predicted crack initiation load of $11.96 \mathrm{kN}$ with the $Y_{R}$ criterion.

due to the existence of the sidegrooves (Figures 18, 19 and 20). This can also be observed from Figure 15, 16 and 17, where $\sigma_{y}$ distributions at the different load levels are shown. The transition point and two different regions can be readily observed from these figures. Similar distributions of stress triaxiality (Figures 21, 22 and 23), are also evident in the transition region.

For $Y_{R}$ and $W_{D}$ distributions at the different load levels, the transition point and two different regions are also observed and $Y_{R}$ and $W_{D}$ attain their respective maximum values at the positions, very close to the transition point.

\section{Conclusions}

From both experimental results and theoretical analysis, the initiation profile of cracks in sidegrooved specimens is much more uniform than in CT specimens without sidegrooves. Due to its existence, the stress state in the crack tip is quite different from that in CT specimens without sidegrooving. The crack initiation and propagation are much smoother that those in CT specimens without sidegrooving. For the sidegrooved CT specimen, the stress state is much more uniform in most of the interior part of the specimen, because the deformation in the thickness direction of material elements in the crack-tip region is constrained by the 
bulk material above and below the sidegroove. The stress triaxiality drops rapidly only in the region close to the sidegroove. Along the crack tip, one unifrom plane strain deformation region in the most interior part and one rapidly changing deformation mode region near the sidegroove are observed, and there is a distinct transition point between these two regions. The damage develops most favorably in a small distance from the sidegroove in the crack tip, which depends on both stress triaxiality and plastic deformation development. The crack will therefore first initiate there, in the crack extension direction, according to the proposed damage failure criteria.

\section{References}

1. C.L. Chow and X.F. Chen, An anisotropic model of continuum damage mechanics based on endochronic theory of plasticity, International Journal of Fracture 55 (1992) 115-130.

2. C.L. Chow and X.F. Chen, Failure analysis of a cracked plate based on endochronic plastic theory coupled with damage, International Journal of Fracture 60 (1993) 49-63.

3. C.L. Chow and X.F. Chen, Three-dimensional fracture analysis of CT specimen with a ductile damage model based on endochronic plasticity theory, International Journal of Fracture 69 (1995) 229-249.

4. H.G. DeLorenzi and C.D. Shih, 3-D elastic-plastic investigation of fracture parameters in side-grooved compact specimen, International Journal of Fracture 21 (1983) 195-220.

5. C.F. Shih et al., Studies on crack initiation and stable crack growth, in Elastic-plastic Fracture, ASTM STP 668 (1979) 65-120.

6. H.C. Wu et al., Further application of endochronic constitutive equation to loading with non-proportional axial-torsional strain-path, International Journal of Non-Linear Mechanics 20, 1 (1985) 41-52.

7. H.C. Wu et al., Analysis of stress response to various strain-paths in axial torsional deformation of metals, Transtactions ASME, Journal of Engineering Materials and Technology 106 (1984) 361-366.

8. O. Watanabe and S.N. Alturi, Internal time, general internal variable and multi yield surface theory of plasticity and creep: a unification of concepts, International Journal of Plasticity 2 (1986) 37-57.

9. F.A. McClintock, A criterion for ductile fracture by the growth of holes, Transactions ASME, Journal of Applied Mechanics (1968) 363-371.

10. J.R. Rice and D.M. Tracey, On the ductile enlargement of voids in triaxial stress fields, Journal of the Mechanics and Physics of Solids 17 (1969) 201-217.

11. J.W. Hancock and M.L. Cowling, Role of state of stress in crack-tip failure processes, Metal Science (1980) 293-304.

12. H. Ziegler, An introduction to thermomechanics, in North Holland Series in Applied Mathematics and Mechanics (1977) Chapter 14. 